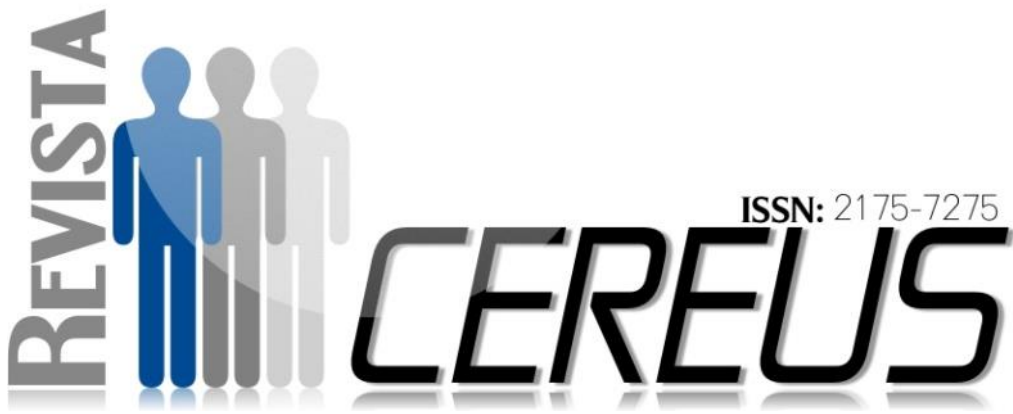

\section{CIÊNCIA, TECNOLOGIA E SOCIEDADE : REFLEXÕES SOBRE O PROBLEMA DO LIXO ELETRÔNICO}

\section{TAVARES, Thiago Daniel Ribeiro ${ }^{1}$}

PEDRO, Wilson José Alves ${ }^{2}$

\section{RESUMO}

O presente artigo, traz uma abordagem interdisciplinar em Ciência, Tecnologia e Sociedade (CTS), buscando refletir atualmente convivemos em um mundo extremamente globalizado e dominado pelas novas tecnologias, que geram grande impacto na vida das pessoas e novos problemas ambientais, tal como a grande quantidade de Lixo Eletrônico, que infelizmente não é descartado, muito menos reciclado de maneira correta. A pesquisa é desenvolvida a partir do método dedutivo e pesquisa exploratória, buscando uma coleta de informações, por meio de materiais bibliográficos, livros, periódicos, mapas temáticos, informações e documentos disponíveis em páginas eletrônicas da rede mundial de computadores, alem do levantamento e análise das normas jurídicas nacionais e internacionais. Foi

1 Doutorando em Ciências, Tecnologia e Sociedade pela UFSCAR, Mestre em Direitos Coletivos e Cidadania pela UNAERP, Advogado e Professor.

2 Pós-Doutor pela Universidade de Lisboa, Doutor e Mestre em Psicologia Social pela PUC/SP, Bacharel e Licenciado em Ciências Socias pela UNESP, professor Adjunto da UFSCAR, e do Programa de Mestrado e Doutorado em Ciências, Tecnologia e Sociedade a UFSCA. E mail: wjapedro@gmail.com. 
empregada a matriz dedutiva, porque, fundamentalmente analisamos a legislação existente buscando, à luz da linguagem, a compreensão, a interpretação e a aplicação mais satisfatória, bem como analisar o problema e impacto que o lixo tecnológico traz à sociedade, bem como as políticas públicas voltadas para a informação e conscientização da população, que devem implicar em uma diminuição desse tipo de lixo e até mesmo revertê-lo em produção de riqueza.

Palavras chave: ciência, tecnologia e sociedade; problema ambiental. lixo eletrônico.

\section{CIENCIA, TECNOLOGÍA Y SOCIEDAD: REFLEXIONES SOBRE EL PROBLEMA MEDIOAMBIENTAL DE RESIDUOS ELECTRÓNICOS}

\section{RESUMEN}

El presente artículo trae un enfoque interdisciplinario en Ciencia, Tecnología y Sociedad (CTS), buscando reflejar que actualmente convivimos en un mundo extremadamente globalizado y dominado por las nuevas tecnologías, que generan gran impacto en la vida de las personas y nuevos problemas ambientales, tal como la gran cantidad de basura electrónica, que desgraciadamente no es descartado, mucho menos reciclado de manera correcta. La investigación se desarrolla a partir del método deductivo e investigación exploratoria, buscando una recolección de informaciones, a través de materiales bibliográficos, libros, periódicos, mapas temáticos, informaciones y documentos disponibles en páginas electrónicas de la red mundial de computadoras, además del levantamiento y análisis de las normas jurídicas nacionales e internacionales. Se empleó la matriz deductiva, porque, fundamentalmente analizamos la legislación existente buscando, a la luz del lenguaje, la comprensión, la interpretación y la aplicación más satisfactoria, así como 
analizar el problema e impacto que la basura tecnológica trae a la sociedad, así como las políticas públicas dirigidas a la información y concientización de la población, que deben implicar en una disminución de ese tipo de basura e incluso revertirlo en producción de riqueza.

Contraseñas: ciencia, tecnología y sociedad; problema medioambiental; residuos electrónicos 


\section{INTRODUÇÃO}

De forma geral, os equipamentos eletrônicos são compostos por vários módulos básicos que geralmente constituem-se de placas e circuitos impressos, cabos, plásticos antichama, comutadores e disjuntores de mercúrio, equipamentos de visualização, como telas de CRT (Cathodic Ray Tube) e de LCD (Liquid Cristal Display), pilhas, baterias, meios de armazenamentos de dados, dispositivos luminosos, condensadores, resistências, relés, sensores e conectores. As substâncias presentes nos resíduos eletrônicos consideradas mais problemáticas do ponto de vista ambiental e da saúde humana são os metais pesados, os gases de efeito estufa, como os CFCs (clorofluorcabonetos), as substâncias halogenadas, bifenilas policloradas, bromatos e ainda o arsênio (Nordic Coucil of Minister in Rodrigues, 2007).

Mas a terminologias mais utilizadas para representar os Resíduos de Equipamentos Elétricos e Eletrônicos, conforme apresentado por Magalhães (2011), sendo denominados pela sigla brasileira (REEE) como: lixo eletrônico, lixo tecnológico, e-lixo, resíduos eletroeletrônicos, resíduos de aparelhos elétricos e eletrônicos, resíduos tecnológicos, sucata eletroeletrônica, sucata eletrônica, sucata tecnológica entre outras afins. $\mathrm{Na}$ terminologia inglesa, os REEE recebem denominação como: e-waste e-scrap, eletronic waste. Internacionalmente não existe uma definição padronizada para este tipo de resíduo (WIDMER et al., 2005).

A quantidade de material presente nos REEE é variada, o que dificulta uma quantificação generalizada existente nesses resíduos, mas a maior parte dos estudos aponta a presença de cinco categorias, são elas: metais ferrosos, metais não ferrosos, vidros, plásticos e outros materiais (ONGONDO, 2011).

De acordo com a ABNT/NBR 10004 (2004), resíduos sólidos - RS são restos das atividades humanas, considerados pelos geradores como inúteis, indesejáveis ou descartáveis, podendo-se apresentar no estado sólido, semi-sólido ou líquido, desde que não seja passível de tratamento convencional.

Já o manual da Secretaria de Desenvolvimento Urbano - SEDU (2001) define Resíduos Sólidos como toda matéria sólida ou semi-sólida 
indesejável e que necessita ser removida por ter sido considerada inútil por quem o descarta, em qualquer recipiente destinado a este ato. Existem várias formas de se classificar os Resíduos Sólidos, sendo que os meios mais comuns são os ligados aos riscos potenciais de contaminação do meio ambiente, e hoje são classificados em três classes: classe I - perigosos, classe II - não-inertes e classe III inertes, e quanto à natureza ou origem: doméstico, comercial, público, especial, (ABNT, 2001).

O lixo eletrônico é considerado um resíduo sólido especial de coleta obrigatória (Brasil, 2010), configurandose como um grave problema para o ambiente e para a saúde, desde sua produção até o seu descarte, pois são constituídos por materiais que possuem metais pesados altamente tóxicos, denominados vilões silenciosos, como o mercúrio, cádmio, berílio e o chumbo. A sua produção pode afetar, tanto os trabalhadores quanto comunidades ao redor dessas indústrias. Além disso, esses resíduos são normalmente descartados em lixões e acabam contribuindo, de maneira negativa, com o meio-ambiente e com os catadores que sobrevivem da venda de materiais coletados nos lixões (SIQUEIRA e MORAES, 2009).

No meio ambiente, os resíduos do lixo eletrônico, ao serem encaminhados para os aterros sanitários, podem causar danos à saúde (FERREIRA e FERREIRA, 2008). Esses resíduos, quando entram em contato com o solo, podem contaminar o lençol freático e, quando submetidos à combustão, acabam poluindo 0 ar. Produtos presentes nesses materiais podem desencadear sérios problemas à saúde humana (MOREIRA, 2007), que podem ser agravados pelos processos de reciclagem bruta, pois muitos poluentes orgânicos persistentes e metais pesados são liberados, podendo se acumular facilmente no organismo por inalação do ar contaminado.

Segundo VIANA (2008), considera-se lixo tecnológico (ou e-lixo) todo aquele gerado a partir de aparelhos eletrodomésticos ou eletroeletrônicos e seus componentes, incluindo os acumuladores de energia (baterias e pilhas), produtos magnetizados, de uso doméstico, industrial, comercial e de serviços, dentre eles os aparelhos de informática e os celulares, que estejam em desuso e sujeitos à disposição final. 
Assim, lixo eletrônico é todo e qualquer tipo de material produzido a partir do descarte de equipamentos eletrônicos, como eletroeletrônicos (computadores, celulares, tablets) e eletrodomésticos (geladeiras, fogões, micro-ondas). O lixo eletrônico, conhecido por e-lixo, RAEE (sigla de

\section{MATERIAIS E MÉTODOS}

Trata-se de um estudo transversal entre Direito e Ciência, Tecnologia e Sociedade (CTS), a pesquisa é desenvolvida a partir do método dedutivo, por meio do levantamento e análise das normas jurídicas nacionais e internacionais sobre meio ambiente e descarte de resíduos sólidos, bem como a influenciando o desenvolvimento de tecnologias que vem gerado um grande acúmulo de lixo eletrônico. Nesse sentido, realizou-se uma coleta de informações, por meio de materiais bibliográficos, livros, periódicos, mapas
Resíduos

de Aparelhos Eletroeletrônicos) e REEE (Resíduos de Equipamentos Elétricos e Eletrônicos), abrange também os componentes que os constituem, como baterias e pilhas (acumuladores de energia) e demais produtos magnetizados.

temáticos, informações e documentos disponíveis em páginas eletrônicas da rede mundial de computadores.

Usamos uma pesquisa exploratória, com coleta de dados utilizando-se a bibliografia conhecida em direito ambiental e rede Internet, fez-se a organização dos dados utilizados e analisados. Foi empregada a matriz dedutiva, porque, fundamentalmente, estase analisando a legislação existente buscando, à luz da linguagem, a compreensão, a interpretação e a aplicação mais satisfatória.

\section{RESULTADOS E DISCUSSÕES}

\subsection{O PROBLEMA AMBIENTAL DO LIXO ELETRÔNICO}

No Brasil vem sendo adotada a política de inclusão digital, ligada diretamente ao consumismo de eletroeletrônicos. $\quad \mathrm{O}$ acesso às tecnologias de informação e comunicação representa uma questão 
mais complexa do que simplesmente colocar um computador com acesso à internet em cada lar. A comunicação democrática deve ser também uma comunicação sustentável. O consumo de bens eletro eletrônicos teve um crescimento considerável nas últimas décadas. Ampliaram-se a variedade de produtos e os modelos oferecidos aos consumidores. $\mathrm{O}$ mercado, atualmente, oferece novos produtos e, por isso, a troca de produtos acontece de maneira mais rápida (CARVALHO et al., 2008). Apesar de existirem empresas especializadas em reciclagem de aparelhos eletroeletrônicos, o número ainda é insignificante, se comparado ao aumento do consumo desses produtos. As vendas desses aparelhos no varejo brasileiro cresceram $29,4 \%$, a cada dia que passa tem aumentado, gradativamente (FERREIRA e FERREIRA, 2008).

Inclusive em reportagem de Fernando Daquino, do site Tecmundo, onde apresentou o levantamento feito pela Accenture o Brasil aparece como o segundo maior consumidor de equipamentos eletrônicos do planeta e também ficou na segunda posição nas intenções de compras de novos aparelhos durante 2013, ficando atrás apenas da China.(DAQUINO, 2013).

Com o avanço acelerado das novas tecnologias e o consumo ativo do capitalismo globalizado, a necessidade de atualização e obtenção de novos aparelhos eletrônicos é imensa e intensa. Neste contexto, eletroeletrônicos considerados obsoletos se tornam cada vez mais presentes, sendo descartados e trocados por novos aparelhos. Este ciclo de mudança pode gerar um grande impacto ambiental, caso o equipamento não passe por um processo adequado de descarte. Hoje o Brasil, produz 36\% do Lixo Eletrônico da América Latina: sendo 1,4 milhão de toneladas em 2014.

Nesse contexto, é importante ressaltar que, se o lixo não for manejado de uma forma correta e apropriada, o mesmo poderá causar danos ao meio ambiente, como na poluição do ar, do solo e da água (JACINTO, 2010). Mas, se o procedimento dessa reciclagem for adequado, com tecnologias apropriadas, contudo, os danos ao meio ambiente se reduzem a níveis relevantes e suportáveis.

A eliminação e descarga de todo o lixo existente no século $X X I$ é 
praticamente impossível, porém, a reciclagem pode evitar maiores danos no ambiente. Portanto, a coleta e a reciclagem de produtos eletroeletrônicos é uma necessidade atual, em termos, não apenas de se conservarem recursos naturais não renováveis através da reciclagem de materiais, mas, também, de se preservar o meio ambiente e evitar que o impacto ambiental negativo seja cada vez maior por esse tipo de produto (CARVALHO et al., 2008).

$\mathrm{Na}$ fabricação de computadores e celulares, a composição química dos resíduos eletrônicos é muito variada, pois são utilizados muitos tipos de metais. Se descartados inadequadamente contaminam o solo, - lençol freático e a água potável. Metais pesados usados em sua composição constituem, portanto, um sério risco para o meio ambiente. Altamente tóxicos, encontramos metais, como: mercúrio, cádmio, berílio e chumbo.

Segundo o Programa Ambiental das Organização das Nações Unidas, 1 (uma) tonelada de sucata eletroeletrônica mista é composta por: $18 \%$, vidro, $15 \%$, placas eletrônicas (ouro, prata, platina). Especificamente os componentes de computadores têm: metais ferrosos 32\%, metais não ferrosos (cádmio etc.) 12\%. Já em 1 (uma) tonelada de lixo eletrônico de componentes de computadores, temos: Ferro entre 35\% e 40\%; Cobre 17\%; Chumbo entre $2 \%$ e $3 \%$; Alumínio $7 \%$; Zinco 4\% a 5\%; Ouro, de 200 a 300 gramas; Prata, de 300 a 1000 gramas; Platina, de 30 a 70 gramas; Fibras Plásticas 15\%; Papel e Embalagens $5 \%$; Resíduos não recicláveis entre 3\% e $5 \%$.

Segundo DIAS, 2003, p.226, "o desenvolvimento econômico e o bemestar do ser humano dependem dos recursos da Terra. $O$ desenvolvimento sustentável é simplesmente impossível se for permitido que a degradação ambiental continue. $O$ desenvolvimento econômico e o cuidado com o meio ambiente são compatíveis, interdependentes e necessários. O desenvolvimento econômico pode e deve coexistir com um meio saudável"

Cabe então à União, Estado e Municípios desenvolverem projetos e estudos para que possam realizar a coleta e o destino final de tais lixos, e/ou ainda fiscalizar as empresas quanto a responsabilidades que possuem em receber de volta todos os produtos que são fabricados e vendidos por elas. É necessário também, destacar que além das empresas, é preciso que os consumidores também sejam fiscalizados, principalmente para não descartar de forma irregular os seus 
parelhos eletrônicos, jogando-os em rodovias, beiras de rios e valas.

Segundo dados da Organização das Nações Unidas (ONU), o Brasil é o país emergente que produz maior volume de lixo eletrônico, isso levando em consideração o poder aquisitivo da classe $\mathrm{C}$ que aumentou nos últimos anos, contribuindo para o aumento do lixo eletrônico. Pela lógica, isso deve ainda ser pior daqui a alguns anos, uma vez que os aparelhos ficam obsoletos muitos rápidos devido às invenções que estão cada vez mais velozes.

Com isso, segundo a ONU é
necessário que os países estejam
preparados para lidar com os lixos
eletrônicos existentes e os que ainda
hão de vir, que não serão poucos, uma
vez que por ano o Brasil abandona 96,8
mil toneladas de computadores. Sendo
o volume inferior apenas ao da china
com 300 mil toneladas, porém, per
capita, o Brasil é o líder. Onde por ano

Com isso, segundo a ONU é preparados para lidar com os lixos eletrônicos existentes e os que ainda hão de vir, que não serão poucos, uma ona 96,8 . Sendo com 300 mil toneladas, porém, per o Brasil joga fora o equivalente 0,5 quilos desse lixo eletrônico. (EXAME,Mundo, 2010).

Por isso, é necessário que tomemos consciência do volume de lixo que estamos produzindo e que sejam tomadas ações que possam amenizar os problemas atuais e os futuros. Uma das alternativas seria o consumo de mercadorias somente o necessário, sempre que possível consertando os que estão em uso, e deixando de comprar cada lançamento que é colocado no mercado.

Infelizmente, a maior parte desse lixo é simplesmente descartada, ou seja, literalmente desperdiçamos, pela simples ausência de informação, treinamento, incentivos e recursos, uma vez que o lixo poderia ser reciclado e gerar riquezas.

\subsection{Lixo eletrônico e a política nacional de resíduos sólidos}

De acordo com a Constituição Federal de 1988, em seu artigo 24, inciso XII, compete concorrentemente à União, aos Estados e ao Distrito Federal legislar sobre a defesa e a proteção à saúde, a limpeza pública, a coleta, o transporte e a disposição dos resíduos. Mas, não se pode confundir a possibilidade de fixar diretrizes gerais a nível federal, com a efetiva execução dessa tarefa sanitária. Em seu artigo 30, a Constituição assegura ao Município autonomia para organizar os serviços públicos de interesse local, ou seja, a União não está obrigada a executar as tarefas de limpeza pública. Mas dada à importância ambiental da matéria, a União não pode se esquivar da função de traçar normas amplas e 
adaptáveis à realidade de nosso país (Machado, 2003).

Não existe uma legislação específica sobre o tema, porém o lixo eletrônico deve obedecer assim os regulamentos existentes para os demais tipos de lixo, pois todos prejudicam o meio ambiente, logo as leis ambientais orientam quanto a utilização correta dos lixos sejam eles quais forem.

Existe um projeto em andamento no Congresso que trata especificamente do lixo eletrônico como resíduo reverso, responsabilizando os fabricantes pelo manejo antes da disposição final. É natural que esse tipo de iniciativa enfrente grande resistência, em especial por parte da própria indústria afinal é ela quem tem que arcar com os custos e a logística. Mas é extremamente necessário para tirar o atraso em que a legislação brasileira se encontra sobre o assunto, e para oferecer uma solução para um problema que cresce a cada ano (e tende a crescer cada vez mais).

O mundo atual se depara com um novo dilema: o que fazer com o lixo eletrônico produzido?. Um grave problema que começa a ganhar espaço para discussões. "o lixo eletrônico geralmente contém substâncias tóxicas, como o mercúrio, cádmio e chumbo, que podem contaminar o meio ambiente, o que leva muitas organizações ecologistas a pressionarem empresas e governos para o seu equacionamento" (CEMPRE, 2007; CIMÉLIA, 2007)

Nas duas últimas décadas leis e normas surgem constantemente no mundo todo para regular o descarte de materiais nocivos ao meio ambiente, como por exemplo as iniciativas e diretrizes ambientais que a União Européia, publicaram em 2007, que procuram controlar e acompanhar os resíduos e a poluição que o processo produtivo pode gerar.

No Brasil também existem algumas orientações legais a esse respeito, como a Resolução do Conselho Nacional do Meio Ambiente (Conama, 1999), órgão ligado ao Ministério do Meio Ambiente, cujo principal foco é o descarte de pilhas e baterias, e a lei 12.305 de 02 de agosto de 2010, que vem complementar as leis Lei, 11.445, de 05 de janeiro de 2007, 9.974, de 06 de junho de 2000, e 9.966, de 28 de abril de 2000, dispondo a respeito de princípios, objetivos, instrumentos, diretrizes, metas e ações adotados pelo Governo Federal, isoladamente ou em regime de cooperação com Estados, Distrito Federal, Municípios ou particulares, com vistas à gestão integrada e ao 
gerenciamento ambientalmente

adequado dos resíduos sólidos.

São princípios da Política Nacional de

Resíduos Sólidos, nos termos do Artigo

6:

I- a prevenção e a precaução;

II- o poluidor-pagador e o protetor-recebedor;

III - a visão sistêmica, na gestão dos resíduos sólidos, que considere as variáveis ambiental, social, cultural, econômica, tecnológica e de saúde pública;

IV - o desenvolvimento sustentável;

$V$ - a ecoeficiência, mediante a compatibilização entre o fornecimento, a preços competitivos, de bens e serviços qualificados que satisfaçam as necessidades humanas e tragam qualidade de vida e a redução do impacto ambiental e do consumo de recursos naturais a um nível, no mínimo, equivalente à capacidade de sustentação estimada do planeta;

VI- a cooperação entre as diferentes esferas do poder público, o setor empresarial e demais segmentos da sociedade;

VII- a responsabilidade compartilhada pelo ciclo de vida dos produtos;

VIII- o reconhecimento do resíduo sólido reutilizável e reciclável como um bem econômico e de valor social, gerador de

trabalho e renda e promotor de cidadania;

IX - o respeito às diversidades locais e regionais;

$X$ - o direito da sociedade à informação e ao controle social;

XI - a razoabilidade e a proporcionalidade.

São objetivos da Política Nacional de Resíduos Sólidos, nos termos do Artigo 07.

I - proteção da saúde pública e da qualidade ambiental;

II - não geração, redução, reutilização, reciclagem e tratamento dos resíduos sólidos, bem como disposição final ambientalmente adequada dos rejeitos;

III- estímulo à adoção de padrões sustentáveis de produção e consumo de bens e serviços;

IV- adoção, desenvolvimento e aprimoramento de tecnologias limpas como forma de minimizar impactos ambientais;

$V$ - redução do volume e da periculosidade dos resíduos perigosos;

VI- incentivo à indústria da reciclagem, tendo em vista fomentar o uso de matérias primas e insumos derivados de materiais recicláveis e reciclados;

VII- gestão integrada de resíduos sólidos;

VIII- articulação entre as diferentes esferas do poder público, e destas com o setor empresarial, com vistas à cooperação técnica e financeira para a gestão integrada de resíduos sólidos;

IX - capacitação técnica continuada na área de resíduos sólidos;

$X$ - regularidade, continuidade, funcionalidade e universalização da prestação dos serviços públicos de limpeza urbana e de manejo de resíduos sólidos, com adoção de mecanismos gerenciais e econômicos que assegurem a recuperação dos custos dos serviços prestados, como forma de garantir sua sustentabilidade operacional e financeira, observada a Lei no 11.445 , de 2007;

$\mathrm{XI}$ - prioridade, nas aquisições e contratações governamentais, para: a) produtos reciclados e recicláveis; b) bens, serviços e obras que considerem critérios compatíveis com padrões de consumo social e ambientalmente sustentáveis;

XII- integração dos catadores de materiais reutilizáveis e recicláveis nas ações que envolvam a responsabilidade compartilhada pelo ciclo de vida dos produtos;

XIII- estímulo à implementação da avaliação do ciclo de vida do produto;

XIV- incentivo ao desenvolvimento de sistemas de gestão ambiental e empresarial voltados para a melhoria dos processos produtivos e ao reaproveitamento dos resíduos sólidos, incluídos a recuperação e o aproveitamento energético;

XV- estímulo à rotulagem ambiental e ao consumo sustentável. 
Mas, no Brasil mesmo que regulamentado em lei não encontramos uma realidade tão favorável à reciclagem do lixo tecnológico. As indústrias e suas representatividades afirmam que a lei não pode impor aos fabricantes-comerciantes metas graduais de coleta de equipamentos eletro eletrônicos. $\mathrm{O}$ argumento utilizado por eles é que o setor produtivo não pode ser responsabilizado por uma meta que precisa da ação dos consumidores em levar seu produto eletrônico a um posto de coleta autorizado. Porém ao buscarmos informações a respeito dessa coleta no interior do Estado de São Paulo, percebemos que são poucos os estabelecimentos comerciais que recolhem esse tipo de produto, além de ainda não existir na população uma consciência a respeito dos malefícios que esse tipo de lixo traz ao meio ambiente.

Hoje a Lei 12.305/2010, que foi regulamentada pelo Decreto 7.404/2010, institui a Política Nacional de Resíduos Sólidos (PNRS). A Norma obriga fabricantes, importadores, comerciantes e distribuidores dos produtos já regulamentados pelo Conama, de lâmpadas fluorescentes e produtos eletrônicos, a implementar um sistema para o retorno de produtos e embalagens após 0 uso pelo consumidor. Esse retorno deverá ser feito de forma independente do serviço público de limpeza.

A lei faz a distinção entre rejeito (não reaproveitáveis) e resíduo (materiais que podem ser reaproveitados ou reciclados). A norma cita todo tipo de lixo: doméstico, industrial, da construção civil, eletroeletrônico, lâmpadas de vapores mercuriais, agropastoril, da área de saúde.

A lei objetiva a não-geração, redução, reutilização e tratamento de resíduos sólidos, bem como destinação final ambientalmente adequada dos rejeitos. Busca, ainda, a redução dos recursos naturais (água, energia, minérios, por exemplo) no processo de produção de novos produtos; trata ainda de ações de educação ambiental, aumentando a reciclagem no país, e de promover a inclusão social, a geração de emprego e renda de catadores de materiais recicláveis. Institui, também, - princípio de responsabilidade compartilhada pelo ciclo de vida dos produtos.

Um dos pontos fundamentais da Política Nacional de Resíduos Sólidos (PNRS) é a chamada logística reversa, 
que se traduz em um conjunto de ações para facilitar o retorno dos resíduos aos seus geradores para que sejam tratados ou reaproveitados em novos produtos. Mas na prática já se

\section{CONCLUSÃO}

O papel da Ciência, Tecnologia e Sociedade, neste contexto é buscar uma nova maneira de conceber a tutela do meio ambiente, e entrar em ação pesquisando, desenvolvendo, e colocando em pratica instrumentos e métodos e tecnológicos que até então as utilizadas para proteção, sem os quais não seriam possíveis. Com 0 passar dos anos deixou de ser vista como fonte de inovação, mas também como fonte de resoluções de problemas, passando a olhar e entender os conflitos gerados por ela e os novos desafios que são trazidos com desenvolvimento.

O CTS apresenta-se como uma das novas formas para se minimizar paradigmas capitalistas (BAZZO, 1998), este movimentos surgidos nas décadas de 60/70 do século $X X$ tinha como objetivo rever a concepção clássica das relações entre Ciência, Tecnologia e Sociedade representada pela equação: +ciência+ tecnologia+ passaram mais de 7 (sete) anos desde que esta lei entrou em vigor e quase nada vem sendo feito para solução do problema do lixo eletrônico.

riqueza+ bem-estar social. (CEREZO, 2004).

Assim os debates sobre Ciências, Tecnologia e Sociedade (CTS) nos últimos anos vem se tornando cada vez maior nas universidade, abordando inclusive as inovações tecnológicas e seus reflexos na sociedade, possibilita articulação de especificidades de cada ciência em um todo (interligação das ciências) e, ao mesmo tempo, visa analisar as consequências dessa relação.

\begin{tabular}{lcc}
\multicolumn{1}{c}{ Neste } & estudo & \multicolumn{2}{c}{ buscamos } \\
estabelecer & relações entre a \\
globalização, & produção & e \\
desenvolvimento tecnológicos, e a
\end{tabular}
ausência de políticas e programas para atender às transformações socioambientais e às novas necessidades frente às mudanças ocorridas. Mas a Implementação e a melhoria no destino final dos resíduos sólidos, em específico o chamado lixo 
eletrônicos, ainda se encontram em passos lentos.

A Lei $n^{\circ} 12305$ de 02/08/10 que trata sobre o destino correto dos resíduos sólidos, e qual a responsabilidade das empresas e das repartições públicas em recolher os mesmos, e fazendo campanhas parar que não sejam descartados em quaisquer lugares, correndo o risco de contaminar águas, solos e contribuir para desenvolvimento de algumas doenças.

Estão havendo mudanças na Legislação a nível nacional, estadual e municipal que favoreçam a perspicácia da fiscalização, porém, ainda se têm muito que fazer a fim de uma melhor conscientização/ação da sociedade nacional que diariamente desperdiça estes recursos preciosos e perigosos.

Como podemos constatar os resíduos tecnológicos possuem um alto teor em metais pesados e até alguns extremamente valorizados, 0 que acarreta uma série de consequências desastrosas voltadas tanto para o meio ambiente quanto para a saúde pública; as possibilidades de manter um ambiente mais harmonioso e saudável fará com que tenhamos uma melhor qualidade de vida socioambiental.

A interdisciplinaridade hoje permite a unicidade das ciências e busca a reciprocidade de suas áreas, ultrapassando a segmentação e a mutilação do ser e do conhecimento, e tem por objetivo desfragmentar, dar vida e problematizar o conteúdo trabalhado. E é esta interdisciplinaridade do CTS que pode ser entendida como um processo no qual se produz uma cooperação articulada de diferentes perspectivas para a interpretação e/ou solução de questões concretas, de ordem intelectual ou prática.

\section{REFERÊNCIAS}

AMADO, Frederico. Direito Ambiental Esquematizado. 5a ed. rev., atual. e ampl. Rio de Janeiro: Forense; São Paulo: Método, 2014.

ANDRADE, Rui Otávio Bernardes; TACHIZAWA, Takeshy; CARVALHO, Ana Barreiros. Gestão ambiental: enfoque estratégico aplicado ao desenvolvimento sustentável. São Paulo: Makron Books, 2000. 
BECK, Ulrich. Sociedade de risco: rumo a uma outra modernidade. Tradução de Sebastião Nascimento. São Paulo: Ed. 34, 2010. 368 p.

BOURDIEU, P. J. Para uma sociologia da ciência. Lisboa: Edições 70, 2008. 166p. BRASIL, Lei 12.305/2010, in: < http:// www.planalto.gov.br > Acesso 03 março 2017. DAQUINO, Fernando - Tec Mundo, 2013. Brasil: um dos maiores consumidores de eletrônicos. Disponível em https://ecommercenews.com.br/artigos/tendenciasartigos/crescimento-do-comercio-eletronico-no-brasil/ Acesso em: 03 março 2017.

EXAME. Mundo, 2010. O Brasil produz muito lixo eletrônico, diz ONU. Disponível em: http://exame.abril.com.br/mundo/brasil-emergente-mais-produz-lixo-eletronico-dizonu-535153/. Acesso em: 03 março 2017.

FERREIRA JMB, FERREIRA AC. A sociedade da informação e o desafio da sucata eletrônica. MOREIRA D. Lixo eletrônico tem substâncias perigosas para a saúde humana. 2007. Disponível em: http://www.htmlstaff.org/ver.php?id=7220. Acesso em: 03 março 2017.

GIDDENS, A., TURNER, J. (orgs.) Teoria social hoje. São Paulo: Editora Unesp, 1999. GIDDENS, A., BECK, U., LASH, S. Modernização reflexiva. São Paulo: Editora Unesp, 1997.

G1. Globo Tecnologia, 2017.2 Disponívelem: <http://g1.globo.com/tecnologia/noticia/2015/12/brasil-produz-36-do-lixo-eletronicodaamerica-latina-mostra-estudo.html > Acesso 03 março 2017. KUHN, Thomas. A estrutura das revoluções científicas. 7. ${ }^{a}$ ed. São Paulo: Perspectiva, 2003. Caps. 1 e 5.

LATOUR, B.; WOOLGAR, S. A Vida de Laboratório: A produção dos fatos científicos. Rio de Janeiro. Relume Dumará. 1997. Cap. 1. 
LÓPEZ CEREZO, J. A. "Ciência, Tecnologia e Sociedade: o Estado da Arte na Europa e nos Estados Unidos". In: SANTOS, L. W. E OUTROS (orgs.) Ciência, Tecnologia e Sociedade: o Desafio da Interação. Londrina: IAPAR, 2004.

MACOHIN, Aline. A sustentabilidade na informática - Reciclagem e Eliminação dos resíduos. Disponível em: < http://www.estig.ipbeja.pt/ ac_direito/luciana_ziglio2.pdf >.Capturado em: FERREIRA, Pedro Peixoto. Maquinas sociais: o filo maquínico e a sociologia da tecnologia. Unicamp - FAPESP. São Paulo, 2004. Disponível em: www.ifch.unicamp.br/cteme/txt/Pedro_ATP.pdf>, acesso em: 03 março 2017.

MAGALHÃES, D. de C. S. Panorama Dos Resíduos De Equipamentos Elétricos E Eletrônicos (REEE): O Lixo Eletroeletrônico - E-Lixo. 2011. 171f. Dissertação (Mestrado em Direito, Relações Internacionais e Desenvolvimento) - Departamento de Direito, Pontifícia Universidade Católica de Goiás, Goiânia, 2011.

MOREIRA D. Lixo eletrônico tem substâncias perigosas para a saúde humana. 2007. Disponível em: http://www.htmlstaff.org/ver.php?id=7220. Acesso em: 03 março 2017.

TORRES, Marco Antônio. Lixo eletrônico: o lado sujo da tecnologia. Anexo XII - no.73Abril de 2008. Disponível em: <www.sciencenet.com.br/scienecepress/73/artigo2_73a-htm>. Acesso em: 03 março 2017.

ONGONDO, F.O.; CHERRETT, T.J. 2011. How are WEEE doing? A global review of the management of electrical and electronic wastes. Journal Waste Management, v. 31 (4), p. 714-730.

RODRIGUES, A. C.. Impactos socioambientais dos resíduos de equipamentos elétricos e eletrônicos: estudo da cadeia pós-consumo no Brasil. Santa Bárbara do Oeste, SP. Dissertação de Mestrado. Faculdade de Engenharia, Arquitetura e Urbanismo da UNIMEP, 2007, p. 303

SIQUEIRA MM; Moraes MS. Saúde coletiva, resíduos sólidos urbanos e os catadores de lixo. Ciência \& Saúde Coletiva 2009; 14(6):2115-2122. 
WIDMER, R. et al. Global perspectives on e-waste: Environmental Impact Assessment Review. Elsevier. Oct. 2001; 19 (5):380-90.

R; et al. Global perspectives on e-waste. Environmental Impact Assessment Review. 25 (2005) 436- 458. Disponível em:. Acesso em 03 março 2017.

Recebido em: 04/09/2016

Aprovado em: 24/09/2017 